\title{
A new species of the shore-fly genus Notiphila Fallén, 1810 (Diptera: Ephydridae) from Bali Island (Indonesia)
}

\author{
Новый вид двукрылых рода Notiphila Fallén, 1810 (Diptera: \\ Ephydridae) с острова Бали (Индонезия)
}

\author{
M.G. Krivosheina ${ }^{1,3}$, A.L. Ozerov ${ }^{2}$ \\ М.Г. Кривошеина ${ }^{1,3}$, А.А. Озеров ${ }^{2}$

\begin{abstract}
${ }^{1}$ A.N. Severtsov Institute of Ecology and Evolution, Russian Academy of Sciences, 119071 Moscow, Russia. E-mail: dipteramarina@rambler.ru

'Институт проблем экологии и эволюции им. А.Н.Северцова РАН, Ленинский проспект, 33, Москва 119071, Россия.

${ }^{2}$ Zoological Museum, Moscow Lomonosov State University, Bol'shaya Nikitskaya 2, Moscow 125009, Russia.

E-mail: ozerov2455@rambler.ru

23оологический музей, МГУ им. М.В. Ломоносова, Большая Никитская ул., 2, Москва 125009, Россия.

${ }^{3}$ corresponding author
\end{abstract}

KEY WORDS: Diptera, Ephydridae, Notiphila obscuripennis, Oriental, new species, description, key.

КЛЮЧЕВЫЕ СЛОВА: Diptera, Ephydridae, Notiphila obscuripennis, ориентальная область, новый вид, описание, определительная таблица.

ABSTRACT. A new shore-fly species, Notiphila (Notiphila) obscuripennis sp.n. from Indonesia, is described. Due to general dark brown coloration the new species resembles Oriental species Notiphila $(N$. $)$ nigrina Krivosheina, 2001, striated face with dark brown carina and parafacials resembles Oriental species $\mathrm{No}$ tiphila $(N$.) nosata Krivosheina, 2001. However by the structure of male terminalia the new species is close to Notiphila (N.) indistincta Krivosheina, 2001, differing from it by longer apically broadened presurstylus covered with setae on basal $2 / 3$. The new species is known from Bali Island only. A key to 21 Oriental species of Notiphila is composed.

РЕЗЮМЕ. Новый вид мух-береговушек, Notiphila (Notiphila) obscuripennis sp.n., описывается из Индонезии. Темной окраской тела новый вид напоминает ориентальный вид Notiphila $(N$.) nigrina Krivosheina, 2001, полосатым лицом с темноокрашенным килем и орбитами он похож на ориентальный вид Notiphila (N.) nosata Krivosheina, 2001. Однако по строению гениталий новый вид близок Notiphila (N.) indistincta Krivosheina, 2001, от которого отличается длинными расширенными на вершине пресурстилями, на 2/3 длины от основания покрытыми щетинками. Новый вид известен только с территории острова Бали. Составлена определительная таблица для 21 ориентальных видов рода Notiphila.

\section{Introduction}

Shore-flies of the genus Notiphila Fallén, 1810 are small, about 3.5-4.5 mm long, greyish-golden flies with brown spots and as a rule transparent clouded wings. The genus is one of the most species rich shorefly genera (Diptera, Ephydridae), comprising over 130 species, among which nearly 40 have been recorded from the Nearctic, 32 - from the Palaearctic, $26-$ from the Afrotropical, 14 - from the Neotropical, $20-$ from the Oriental and 5 - from the Australasian/Oceanian Regions [Bock, 1988; Cogan, 1968; Mathis, 1979; Mathis, Zatwarnicki, 1995; Krivosheina, 1998, 1999, 2001, 2003, 2010; Krivosheina, Ozerov, 2015].

Adults of Notiphila can be easily distinguished from those of the other genera of Ephydridae by the narrowed mouth opening, the structure of the wing (costal vein running along the wing margin only to reach vein $R_{4+5}$ ), and the grey-brown body. The mode of life of the Notiphila species is typical for shore flies: adults occur in mass in the shore zone of water bodies, slowly moving over the humid silt substrate or over parts of plants floating on the water surface; they can frequently be observed seating on stems head first. Larvae inhabit the rhizosphere, feed on detritus, breath with oxygen of plant tissues, periodically piercing roots with a tapered spiniform spiracle [Krivosheina, 1993].

A new species of the genus Notiphila was discovered in the material collected by D.I. Gavryushin in Indonesia; its description is given below.

How to cite this article: Krivosheina M.G., Ozerov A.L. 2019. A new species of the shore-fly genus Notiphila Fallén, 1810 (Diptera: Ephydridae) from Bali Island (Indonesia) // Russian Entomol. J. Vol.28. No.3. P.323-327. doi: $10.15298 /$ rusentj.28.3.12 

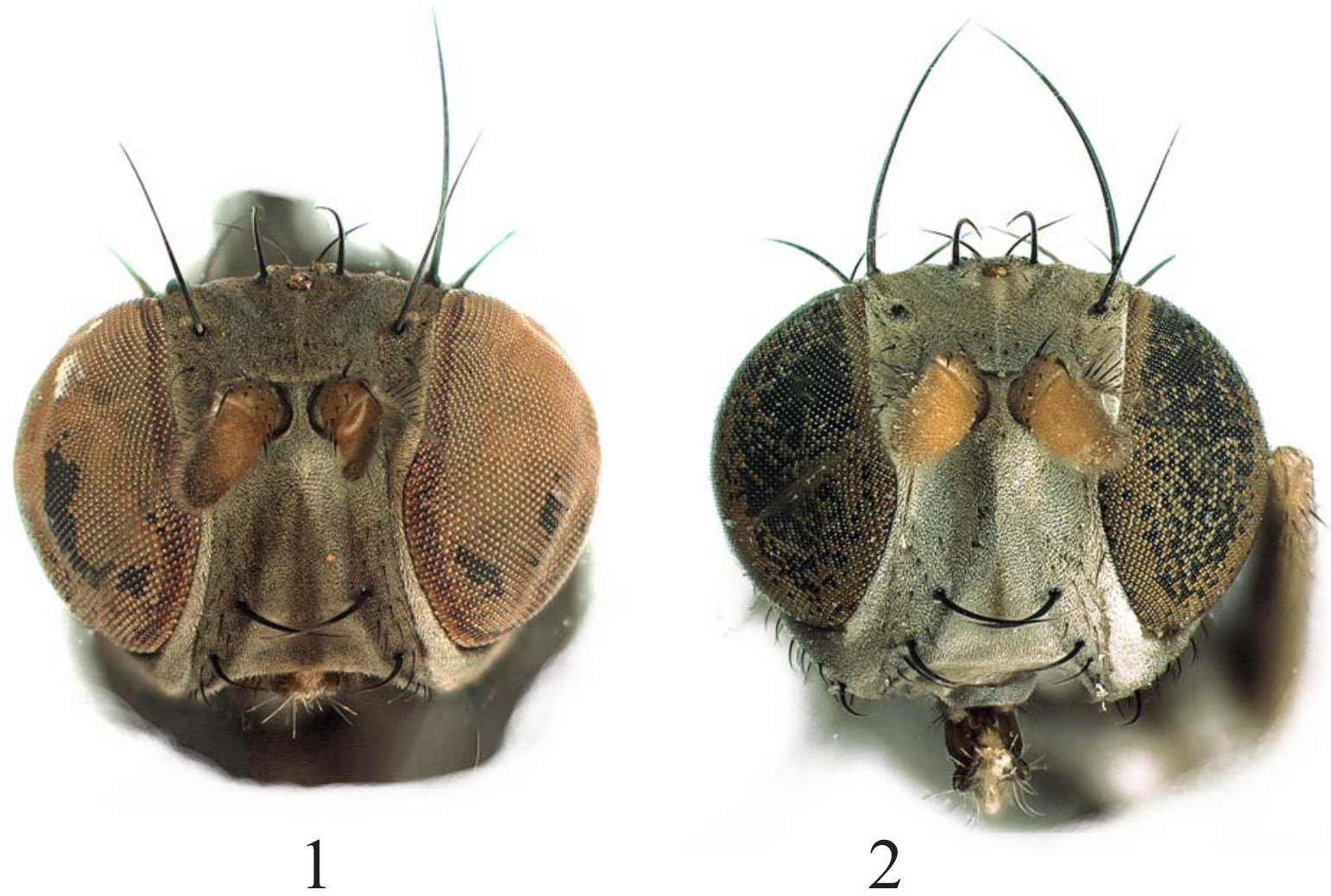

Figs 1-2. Notiphila (Notiphila) obscuripennis sp.n. (1) and N. indistincta Krivosheina, 2001 (2), head, anterior view. Рис. 1-2. Notiphila (Notiphila) obscuripennis sp.n. (1) и N. indistincta Krivosheina, 2001 (2), голова, спереди.

\section{Materials and methods}

The descriptive terminology follows that used by Mathis \& Zatwarnicki [2007]. Dissections of male terminalia were performed using the method of the same authors with some exceptions: microforceps were used to remove the most end of male abdomen, which was macerated in a potassium or sodium hydroxide solution. Cleared genitalia were rinsed in distilled water and then in $70 \%$ ethanol, the figures were made from genitalia placed to glycerin. Rest of abdomen and genital structures were placed in a plastic microvial filled with glycerin and attached to the pin supporting the insect from which it was removed.

The holotype and paratypes of the new species are deposited in the collection of the Zoological Museum of Moscow State University (ZMUM).

\section{Taxonomic part}

Notiphila (Notiphila) obscuripennis Krivosheina et Ozerov, sp.n.

Figs 1, 3, 4.

MATERIAL. Holotype $0^{7}$, INDONESIA, Bali, Tabanan, Kediri, Pantai Kedungu env., $8.608^{\circ} \mathrm{S}, 115.083^{\circ} \mathrm{E}, 10 \mathrm{~m}$ a.s.l., 25.VIII. 2018 (D. Gavryushin). Holotype male mounted together with paratype female on the same pin. Other paratype $\sigma^{2}$, with the same label.
Paratype male specimen is dissected, male terminalia are preparated and placed inside plastic tube filled with glycerin.

DIAGNOSIS. Due to general dark brown coloration the new species resembles Oriental species $\mathrm{No}$ tiphila (N.) nigrina Krivosheina, 2001, striated face with dark brown carina and parafacials resembles Oriental species Notiphila (N.) nosata Krivosheina, 2001. However by the structure of male terminalia the new species is close to Notiphila (N.) indistincta Krivosheina, 2001 (Figs 5, 6), although significantly differing from it by external characters: firstly by dark brown wings with dark veins, coloration of face and thorax, and long apically broadened presurstylus.

DESCRIPTION. Body medium-sized, length 3.5$3.8 \mathrm{~mm}$ in males, $4.0 \mathrm{~mm}$ in female, wing $3.5 \mathrm{~mm}$. General coloration dark brown with blackish spots at bases of setae.

Head. Frons brown-grey, orbits and ocellar triangle brown-black. Face grey-brown, carina dark brown, parafacial dark brown. Palpus yellow-orange. Antennae orange, postpedicel darkened dorsally. Arista with 11-12 long rays. One strong posterior fronto-orbital seta pointing posteriorly; one fine and very short anterior frontoorbital seta pointing anteriorly. Postfrontal index (height to width ratio of frons) 0.6 , prefrontal index (ratio of height of face to its width below antennae) 1.4, head index (eye-to-gena height ratio) 7:1. Face with 3 strong setae, the upper the longest, the lowest the shortest 


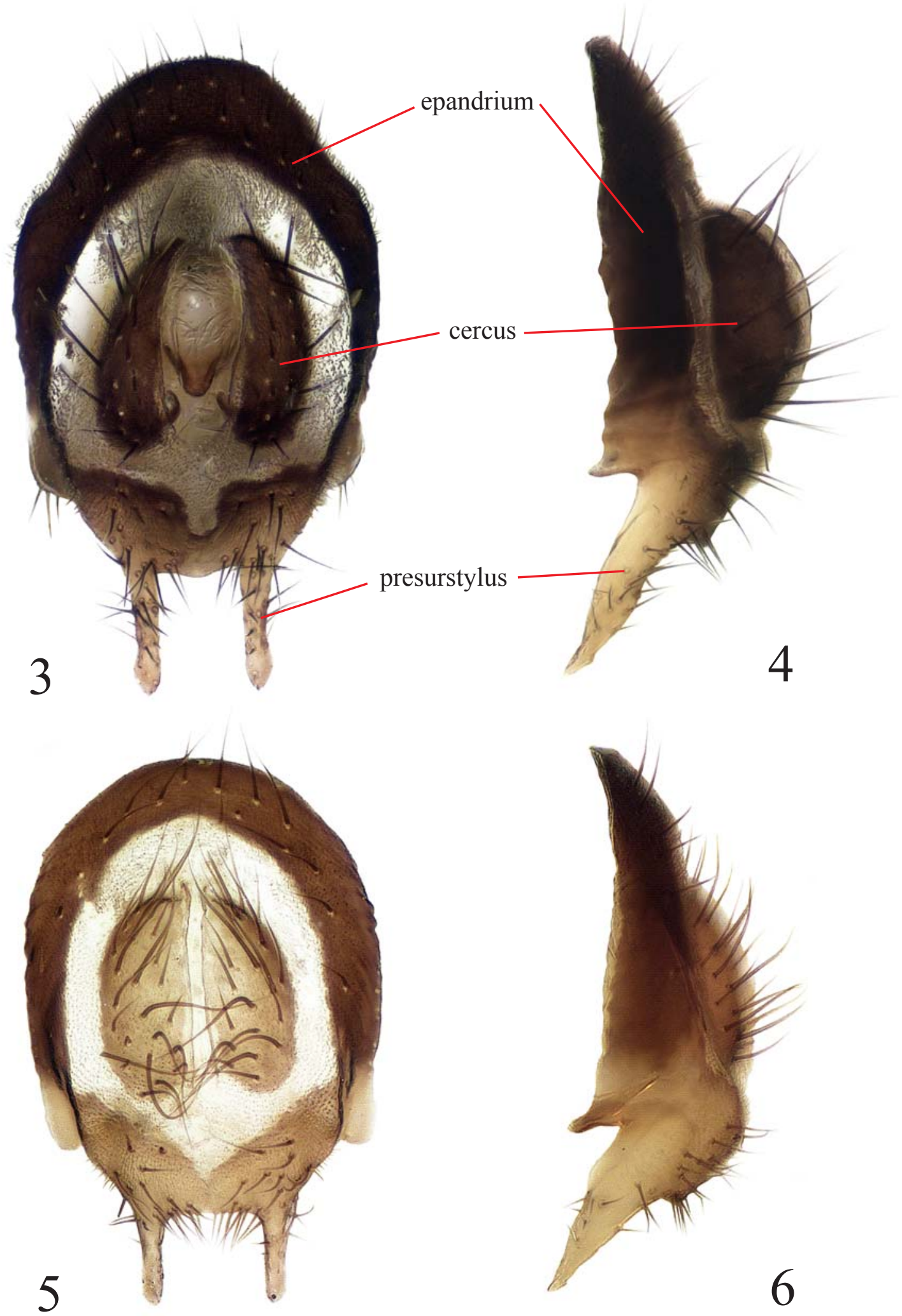

Figs 3-6. Notiphila (Notiphila) obscuripennis sp.n. $(3,4)$ and N. indistincta Krivosheina, 2001 (5, 6): 3, 5 - epandrium, cercus and presurstylus, dorsal view; 4, 6- same, lateral view.

Pис. 3-6. Notiphila (Notiphila) obscuripennis sp.n. $(3,4)$ и N. indistincta Krivosheina, $2001(5,6): 3,5$ - эпандрий, церки и пресурстили, сверху; 4, 6 - то же, сбоку. 
and a little thinner and 1 or 2 fine short hairs below setae.

Thorax. Scutum brown, with dark spots at bases of all setae; anepisternum brown-golden with median dark brown wide band and dark points at bases of 2 setae; katepisternum grey with golden spot around seta. Scutellum brown, oblong, 1.2 times as long as wide, with 4 long setae and covered with sparse short hairs. Haltere yellow. All coxae dark, densely grey microtomentose; femora dark with yellow apices; basal coloration of all tibiae yellow; hind tibia with black band in the middle. Fore tarsi yellow, darkened; mid and hind tarsi yellow. Fore coxa with 2 setae and pubescence, mid coxa with 1 strong seta and a row of shorter setae. Fore femur ventrally with 3-4 long setae. Mid femur with 2-4 strong long setae on inner surface, this row also including 2-3 short setae; anteroventral surface with 2 rows of short spiniform setae. Mid tibia with 3 strong dorsal setae.

Wings brown, section between costal vein and vein $R_{4+5}$ darker. Veins dark brown.

Abdomen. Grey; tergites 1-4 with two median dark brown spots; tergite 5 brown. Spots arranged to form narrow, pale grey longitudinal stripe in median part of abdomen. Posterior margins of tergites grey with black points at bases of posterior marginal setae. Male terminalia: epandrium in dorsal view oval, presurstylus long and narrow, broadened apically, with many relatively strong setae except the apex (Fig. 3); cercus narrow in dorsal view, convex in lateral view, relatively long and covered with setae (Figs $3,4)$; presurstylus in lateral view long, almost $1 / 2$ as long as epandrium, pointed apically, with irregular rows of setae (Fig. 4); subepandrial plate in lateral view rod-like with broadened end; aedeagus large and tubular, of same width basally and apically, with dorsobasal short process; phallapodeme narrow; gonite angulate, T-shaped; hypandrium in dorsal view broadly U-shaped.

ETHYMOLOGY. The species name is given because of dark brown coloration of wing.

BIOLOGY. The specimens were collected near small pond.

\section{A Key to the Oriental SPECIES OF the genus Notiphila}

1. Frons with velvety-black spots . ...................... N. (Agrolimna) puncta de Meijere, 1911

- Frons without spots ......................................................... 2

2. Costal vein with long spines length of which exceeding thickness of vein ............................................................ 3

- Costal vein without long spines ...................................... 4

3. Face flat. Gena low. Head index 5:1. Scutum with rounded dark spots at bases of setae, occasionally with median longitudinal brown stripe and oval spots

......... N. (Notiphila) dorsopunctata Wiedemann, 1824

- Face concave, gena wide, head index 3:1, scutum grey ...

N. (Notiphila) setosa Krivosheina, 2001

4. Face without strong setae, with fine hairs or pubescence only......

- Face with strong setae ............................................... 7

5. Scutum with dark median stripe and interrupted stripes along acrostichal lines; face with 8 fine hairs

N. (Agrolimna) freyi Krivosheina, 2001
- Scutum unicolor, face with 3 fine hairs or with pubescence

.

6. Face pubescent; frons narrow, longer than wide; scutum greyish golden with 2 brown longitudinal stripes occasionally poorly developed; median abdominal segments with 4 elongate dark spots

N. (Notiphila) puberula Krivosheina, 2001

- Face with 3 hairs, frons transverse; scutum brownish, median abdominal segments with 4 small triangular dark spots ......................... N. (Notiphila) nubila Dahl, 1973

7. Antenna black, postpedicel yellow on inner surface ..... 8

- Antenna yellow or orange ......................................... 10

8. Fore legs black .

N. (Notiphila) indica Krivosheina, 2001

- Fore legs at least partly yellow ......................................... 9

9. Face with 3 setae, head index 5:1; body brownish-black .. N. (Notiphila) nigrina Krivosheina, 2001

- Face with 2 setae, head index 7:1; scutum with brown longitudinal stripe

N. (Notiphila) tschungseni Canzoneri, 1993

10. Gena high, head index 3:1 ...................................... 11

- Gena low, head index exceeding 3:1; height of gena equal to or less than width of postpedicel 12

11. Face with 3 setae, scutum with brown median stripe and with spot on anepistermum; presurstylus short and broad N. (Notiphila) flava Dahl, 1973

- Face with 2 (rarely with 3 ) setae; scutum grey without stripes or spots; presurtylus narrow

N. (Notiphila) impunctata de Meijere, 1908

12. Scutellum with 2 brown dorsal spots occasionally merging into one spot

N. (Notiphila) scutellata Krivosheina, 2001

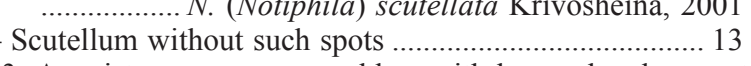

13. Anepisternum grey or golden, with brown band or spot in central part ............................................................. 14

- Anepisternum brown at least in lower part .................... 17

14. Head index 5:1; abdominal spots formula $0-2-4-2$, abdominal tergite 5 grey N. (Notiphila) insularis Grimshaw, 1901

- Gena lower, head index 6:1; abdominal tergites usually with 2 large dark spots .......

15. Presurstylus tapered apically and outcurved; antenna yellow; thorax mottled golden-brown ....

N. (Notiphila) similis de Meijere, 1908

- Presurstylus straight; antennae orange ........................... 16

16. Wings hyaline, veins yellow; face grey (Fig. 2); presurstylus not broadened apically (Fig. 5)

N. (Notiphila) indistincta Krivosheina, 2001

- Wings brown with section between costal vein and vein $R_{4+5}$ darker, veins dark brown; face grey with brown carina and parafacial (Fig. 1); presurstylus broadened apically (Fig. 3) ……..................... N. (Notiphila) obscuripennis sp.n.

17. Anepistrnum mottled brown; abdominal tergites with 2 large indistinct spots

N. (Notiphila) simalurensis de Meijere, 1916

- Anepistrnum brown in lower part ................................. 18

18. Anepistrnum with rounded spot at centre; face grey; abdominal tergites with 4 narrow elongate spots ...........

N. (Notiphila) phaea Hendel, 1914

- Anepisternum with brown band ................................... 19

19. Face with brown carina; abdomen with 2 large spots, grey longitudinal median stripe distinct....

N. (Notiphila) nosata Krivosheina, 2001

— Face uniformly golden-grey or of different color; abdominal tergites with 4 spots 
20. Face dark grey with pale carina and parafacial; gena low, head index 7:1; abdominal tergite 4 with 4 elongate spots and 6-8 long reclinate setae.....

N. (Notiphila) thaica Krivosheina, 2010

— Face uniformly golden-grey, gena higher, head index 5:1; abdominal tergite 4 with 2 small square spots, without long setae

N. (Notiphila) philippinensis Cresson, 1948 N. (Notiphila) sternalis Thomson, 1868

\section{Discussion}

Notiphila is one of the most investigated genera among Ephydridae. The revisions of Afrotropical [Cogan, 1968], Australian [Bock, 1988], Nearctic [Mathis, 1979], Palaearctic [Krivosheina, 1998] and Oriental Regions [Krivosheina, 2001] have been fulfilled up to the present time. However not all "old" primary types of the genus were found and investigated, as a result some discoveries like belonging of the syntype specimens of Notiphila meridionalis (Rondani, 1856) to the genus Brachydeutera Loew, 1863, still happen [Stucke, 2011]. The fauna of Oriental region included 21 species [Krivosheina, 2001]. After synonymization of $N$. canescens Miyagi, 1996 with $N$. insularis Grimshaw, 1901 [Krivosheina, 1999] and $N$. spinosa Cresson, 1948 with $N$. dorsopunctata Wiedemann, 1824 [Krivosheina, 2003] the number of species reduced to 19 . One more new to science species, Notiphila thaica Krivosheina, 2010 was described later [Krivosheina, 2010]. Taking into account the new species described in this article the number of Notiphila species of Oriental region reached 21 again.

Acknowledgements. We are very grateful to Dr. Nikita Vikhrev (ZMUM) who organized the expedition to Bali Island and Mr. Dmitry Gavryushin who collected the new species. The investigation was fulfilled within the state project AAAAA18-118042490060-1 (M.G. Krivosheina) and the state project No AAAA-A16-116021660077-3 (A.L. Ozerov).

\section{References}

Bock I.A. 1988. The Australian species of Paralimna and Notiphila (Diptera: Ephydridae) // Invertebtrate Taxonomy. Vol.2. P.885-902.

Cogan B.H. 1968. A revision of the Ethiopian species of the tribe Notiphilini (Diptera: Ephydridae) // Bulletin of the British Museum (Natural History), Entomology. Vol.21. No.6. P.281365.

Krivosheina M.G. 1993. Larvae of the Shore Flies of the Genera Notiphila Fll. and Dichaeta Mg. (Diptera, Ephydridae) and Their Significance for Understanding the Position of these Genera in the Classification // Entomological Review. Vol.72. No.1. P.222-230.

Krivosheina M.G. 1998. Revision of the Shore-fly Genus Notiphila Fallén of Palaearctic (Diptera, Ephydridae) // An International Journal of Dipterological Research. Vol.9. No.1. P.31-63.

Krivosheina M.G. 1999. Some Taxonomic Notes on Ephydridae (Diptera) // An International Journal of Dipterological Research. Vol.10. No.1. P.45-49.

Krivosheina M.G. 2001. A Revision of the Shore-fly Genus Notiphila Fallén, 1810 of Oriental Region (Diptera, Ephydridae) // Russian Entomological Journal. Vol.10. No.1. P.75-92.

Krivosheina M.G. 2003. The Results of the Investigation of the Type Specimens of Notiphila spinosa Cresson, 1948 (Diptera, Ephydridae) // Russian Entomological Journal. Vol.12. No.3. P.347-348.

Krivosheina M.G. 2010. A new species of the shore-fly genus Notiphila (Diptera, Ephydridae) from Thailand // Entomological Review. Vol.90. No.5. P.664-667.

Krivosheina M.G., Ozerov A.L. 2015. A new species of the shorefly genus Notiphila Fallén, 1810 (Diptera: Ephydridae) from Indonesia // Zootaxa. Vol.3974. No.4. P.595-598.

Mathis W.N. 1979. Studies of Notiphilinae (Diptera: Ephydridae), I: Revision of the Nearctic species of Notiphila Fallén, excluding the caudata Group // Smithsonian Contributions to Zoology. No.287. P.1-111

Mathis W.N., Zatwarnicki T. 1995. World Catalog of Shore Flies (Diptera: Ephydridae) // Memoires of Entomology, International. Vol.4. P.1-423.

Mathis W.N., Zatwarnicki T. 2007. A revision of species of the genus Dichaeta Meigen (Diptera: Ephydridae) // Annales Zoologici (Warsaw). Vol.57. No.4. P.783-822.

Stucke J.-H. 2011. Taxonomic remarks on Notiphila meridionalis Rondani (Diptera: Ephydridae) // Studia Dipterologica. Vol.18. No.1-2. P.194-196. 